\title{
A Case-Based Clinical Approach to the Investigation, Management and Screening of Families with BRCA2 Related Prostate Cancer
}

\section{Bradley King' \\ Jana McHugh ${ }^{2}$ \\ Katie Snape ${ }^{3}$}

'Institute of Medical and Biomedical Education, St. George's, University of London, London, UK; ${ }^{2}$ Department of Oncogenomics, Institute of Cancer Research, London, UK; ${ }^{3}$ Department of Clinical Genetics, St George's University Hospitals NHS Foundation Trust, London, UK
Correspondence: Katie Snape Department of Clinical Genetics, Basement, Jenner Wing, St George's Hospital, London, SWI7 0QT, UK Tel +442087255333

Email ksnape@sgul.ac.uk

\begin{abstract}
B R C A 2$ is the most commonly implicated DNA damage repair gene associated with inherited prostate cancer. $B R C A 2$ deficient prostate cancer typically presents at a younger age, is more poorly differentiated, and is associated with worse survival outcomes than non- $B R C A 2$ associated prostate cancer. Despite these unfavourable prognostic implications, poly-ADP ribose polymerase inhibitors and platinum-based chemotherapy have been identified as potent targeted therapeutic agents towards $B R C A 1 / 2$ deficient cancer cells. This review article explores the literature surrounding $B R C A 2$-related prostate cancer through a familial clinical scenario. The investigation, diagnosis and management of $B R C A 2$ deficient prostate cancer will be explored, alongside the implications of the identification of a germline pathogenic $B R C A 2$ variant within a family, cascade screening and prostate cancer surveillance in unaffected male $B R C A 2$ carriers. A greater understanding of the molecular pathogenesis of DNA damage repair gene deficient prostate cancer, coupled with new treatment paradigms and widened access to both somatic and germline genetic analysis for prostate cancer patients and their families will hopefully enable the robust implementation of high quality evidence-based clinical pathways for both the management and identification of $B R C A 2$ deficient prostate cancer and improved screening, early detection and prevention strategies for individuals at increased genetic risk of prostate cancer.
\end{abstract}

Keywords: prostate cancer, BRCA, genomics, PARP inhibitors, clinical management

\section{Introduction}

Prostate cancer (PC) is the most common cancer in males in the UK and remains one of the leading causes of morbidity and mortality within the cancer patient population, with approximately 1.4 million new diagnoses and around 375,000 associated deaths globally in 2020. ${ }^{1}$ The majority of PC occurs sporadically in males over the age of 65 . These cancers are driven by tumour-specific genetic changes that drive oncogenesis (somatic pathogenic variants). Twin studies in Scandinavia have suggested that just over half of predisposition to PC may be due to genetic factors. ${ }^{2}$ Currently, the majority of these are common variants contributing to polygenic inheritance, where multiple genetic loci associated with a low-moderate risk increase an individual's lifetime risk of developing PC. A smaller proportion of cases are due to single moderate-high risk genetic variants. ${ }^{3}$ These are primarily pathogenic variants in DNA damage repair (DDR) genes.

Common variants predisposing to PC are predominantly identified through large-scale Genome Wide Association Studies (GWAS), and over 160 single 
nucleotide polymorphisms (SNPs) associated with PC have been identified. ${ }^{4}$ Whilst individually these SNPs are low risk (relative risk $\sim 1.1-1.3$ ), their use in combined polygenic risk scores is likely to facilitate future identification of more men at risk of PC in clinical practice and they have given significant insights into the biological pathways and networks underlying oncogenesis. ${ }^{4,5}$

DNA sequencing of germline DNA in patients with PC is the mainstay of identification of rarer moderate-high penetrance monogenic variants predisposing to PC. In the main, these genes act within DNA damage repair pathways and include BRCA1, BRCA2, ATM, PALB2, HOXB13 as well as mismatch repair genes indicated in Lynch Syndrome, particularly $\mathrm{MSH} 2{ }^{6-10}$ Germline variants in $B R C A 2$ have been implicated in the pathogenesis of $1-2 \%$ of PCs and have been reported to confer an increased relative risk of approximately $2.4-8.6$-fold in men below the age of 65 years, making it the most commonly implicated DDR gene associated with inherited PC. ${ }^{3,11-13}$ BRCA2 germline variants confer a $20 \%$ lifetime risk of developing PC and are associated with not only early-onset disease, but also a worse prognosis than noncarriers of $B R C A 2$ germline variants. ${ }^{3,6,7,11,14-18}$

The BRCA2 gene, located on chromosome 13q12.3, is tumour suppressor gene that follows an autosomal dominant pattern of inheritance. $B R C A 2$ encodes for a protein which helps to repair double-stranded DNA (dsDNA) breaks through homologous recombination (HR) repair. Most $B R C A 2$ pathogenic variants are protein truncating variants leading to the formation of a truncated, nonfunctional protein. BRCA2 deficient PC in most cases, occurs due to biallelic loss of the $B R C A 2$ gene within the tumour (loss of both copies of the BRCA2 gene). This can occur in the tumour alone or can be due to the inheritance of a germline monoallelic pathogenic variant, with loss of the second allele within the tumour in accordance with Knudson's two-hit hypothesis. Therefore, men with inherited $B R C A 2$ variants have a higher propensity for developing $\mathrm{PC}$ if the one remaining unaffected $B R C A 2$ allele develops a second single somatic pathogenic variant leading to oncogenesis. ${ }^{7,19}$ There are rare exceptions, where the mutant allele only is lost in a tumour, leaving the normal copy implying that in some cases a haplo-insufficiency mechanism leads to tumour development. ${ }^{20}$

In this review article, we will consider $B R C A 2$-related PC, considering a hypothetical family (Figure 1) and discuss the investigation, diagnosis and management of

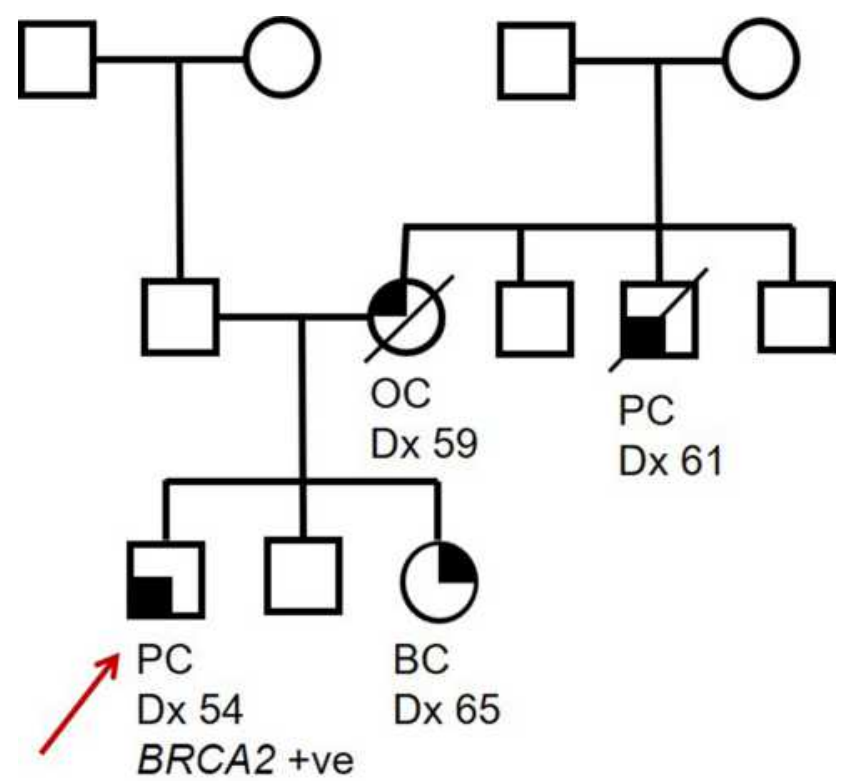

Figure I Pedigree of a hypothetical family carrying a pathogenic BRCA2 germline variant. Proband (indicated by red arrow) was diagnosed with PC at 54 years, proband's sister was diagnosed with BC at $4 \mathrm{I}$ years and proband's mother (deceased) was diagnosed with $\mathrm{OC}$ at 59 years. A maternal uncle (deceased) was diagnosed with PC at 61 years. Circles indicate females, squares indicate males. A line through a figure indicates that individual is deceased.

Abbreviations: PC, prostate cancer; BC, breast cancer; OC, ovarian cancer; Dx, diagnosis.

BRCA2 deficient $\mathrm{PC}$, alongside the implications of the identification of a germline pathogenic variant in the $B R C A 2$ gene within a family and PC surveillance in unaffected male $B R C A 2$ carriers. This clinical case-based approach is intended to summarise the implications of a diagnosis of BRCA2 deficient prostate cancer for both the proband and wider family and is complementary to more comprehensive systematic reviews ${ }^{21-27}$ providing more in depth scientific review on the diagnosis and management of DDR gene deficient prostate cancer.

\section{Identification and Management of BRCA2 Deficient Prostate Cancer}

The proband in Figure 1 has just been diagnosed with PC at a relatively young age. There are fortunately a number of different treatment options for PC which range from conservative management with active surveillance to radical medical and/or surgical options. The selection of an appropriate clinical treatment plan is dependent on a number of factors which include (but are not limited to) pre-existing patient risk factors, tumour grading and staging, lifeexpectancy and patient preference. Mainstay treatment options for low-high risk localised PC include active surveillance, radical prostatectomy, radiotherapy (external 
beam or brachytherapy) and androgen-deprivation therapy, and high intensity focused ultrasound. ${ }^{11,28,29}$

Compared to BRCA proficient PC (BRCA2-ve), $B R C A 2$ deficient PC (BRCA2+ve) typically presents at a younger age, is more poorly differentiated and aggressive, and is associated with worse survival outcomes than non-BRCA2 associated PC. Evidence for the more adverse clinical presentation comes from multiple studies. Carter et $\mathrm{al}^{30}$ provided evidence that germline $B R C A 2$ carriers are more likely to be reclassified from Gleason score (GS) 3+3 at diagnosis to $\mathrm{GS} \geq 4+3(4.1 \%$ (BRCA2+ve) vs $0.7 \%$ (BRCA2-ve), $(\mathrm{p}=0.01))$ versus GS $3+4 \quad(2.1 \%$ (BRCA2 $+\mathrm{ve})$ vs $0.6 \%$ (BRCA2-ve), $(\mathrm{p}=0.03))$. They indicated that $B R C A 2$ carriers have more unfavourable prognostic indicators and a greater chance of progression from localised PC to metastatic castration-resistant PC (mCRPC) (which has a median survival rate 18-36 months).

A systematic review by Gleicher et $\mathrm{al}^{31}$ compared PC characteristics in both carriers of the $B R C A 2$ germline variant (BRCA2+ve) and non-BRCA2 carriers (BRCA2-ve). It was found that $B R C A 2$ carriers had higher prostate-specific antigen (PSA) values at diagnosis $(\mathrm{p}<0.001)$, a higher proportion of PCs with a Gleason score $>7$ (64\% (BRCA2+ve) vs $49 \%$ (BRCA2-ve), $(\mathrm{p}<0.001))$. In addition, a higher proportion of BRCA2+ve tumours have T3/T4 staging (41\% (BRCA2+ve) vs $29 \%$ (BRCA2-ve), $(\mathrm{p}<0.001))$ and higher rates of metastatic disease at diagnosis $(26 \%$ (BRCA2+ve) vs $8 \%$ (BRCA2-ve), $(\mathrm{p}<0.001))$. A study by Wokołorczyk et $\mathrm{al}^{32}$ found that $\mathrm{PC}$ with Gleason scores $>8$ were more likely in men carrying germline $B R C A 2$ variants than in non-carriers (75\% (BRCA2+ve) vs 22\% (BRCA2-ve), $(\mathrm{p}<0.05))$. This group stipulated that $B R C A 2$ carriers had a lower mean age than non-BRCA2 carriers at the time of their PC diagnosis (57 years $(\mathrm{BRCA} 2+\mathrm{ve})$ vs 61 years $(\mathrm{BRCA} 2-\mathrm{ve}), \mathrm{p}=0.3)$. In a study by $\mathrm{Na}$ et $\mathrm{al},{ }^{33} 6.07 \%$ of men with lethal $\mathrm{PC}$ were later identified as carriers of pathogenic variants in either $B R C A 1 / 2$ or $A T M$ compared to $1.44 \%$ of men with localised PC who were carriers of these variants $(\mathrm{p}=0.0007)$.

The treatment pathway is therefore more challenging in these patients. More potent therapeutic agents are often considered rather than more conservative measures with active surveillance. ${ }^{7,8,11,28,34-36}$

\section{Therapeutic Options in BRCA2 Deficient Prostate Cancer}

Whilst a diagnosis of $B R C A 2$ deficient PC has unfavourable prognostic implications, the understanding of the underlying molecular defect leading to oncogenesis enables a precision medicine approach targeting the DDR deficient (DDRd) cancer cells specifically. Poly-ADP ribose polymerase (PARP) inhibitors and platinum-based chemotherapeutic agents have been identified as particularly valuable treatment options for cancers brought about from either somatic or germline variants in DDR genes such as BRCA2 and may become standard of care for $B R C A 2$ deficient PC patients in the near future. ${ }^{3,17,19,37-39}$

\section{PARP Inhibitors}

One of the main driving forces for oncogenesis in BRCA1/ 2 deficient cells relates to the disruption of the HR DNA repair pathway as a result of biallelic $B R C A$-loss. In cells lacking functional $B R C A$ proteins, $\mathrm{HR}$ is impaired, forcing the cell to utilise alternative DDR mechanisms such as (i) non-homologous end joining (NHEJ) which is less accurate than $\mathrm{HR}$ and thus susceptible to errors and (ii) single strand (ss) DNA break repair, which is mediated by the PARP enzymes, PARP1 and PARP2. Increased dependency on PARP-mediated DDR pathways makes BRCA1/ 2 deficient cells suitable targets for PARP inhibitor therapy, which would disable PARP1 and PARP2. This forces the $B R C A$ deficient cells to try to mend DNA damage in the double strand (ds) DNA pathway, which they are unable to do due to the $B R C A$ deficiency. Accumulation of these ds-DNA breaks increases cell stress, leading to cell cycle arrest and cell death via apoptosis. This process is known as synthetic lethality. ${ }^{40-43}$

PARP inhibitors were first investigated as a novel treatment approach for $B R C A$ deficient tumours in 2005 and have since proven to be of clinical benefit, with pharmaceuticals such as rucaparib and olaparib being approved for $\mathrm{mCRPC}$ treatment in the US following the results of clinical trials such as TOPARP-A, TOPARP-B, PROfound and TRITON (Table 1). ${ }^{17,41,44-49}$ Whilst PARP inhibitor use has been documented as a beneficial treatment for $B R C A$ deficient $\mathrm{mCRPC}$ patients, resistance to these drugs is not uncommon and may occur via the acquisition of somatic $B R C A 1 / 2$ variants in the germline allele which restore the reading frame (ie $B R C A$ reversion variants) and thus the normal functioning of the $B R C A$ protein. ${ }^{50-56}$ Case reports by Carneiro et $\mathrm{al}^{57}$ and $\mathrm{Ma}$ et $\mathrm{al}^{58}$ have identified multiple reversion variants in $B R C A 2$ deficient mCRPC patients who developed resistance to olaparib treatment. Ma et $\mathrm{al}^{58}$ postulated that the efficacy of PARP inhibitor therapy may be reliant on the proportion of DDR variants in relation to other variants present within 


\begin{tabular}{|c|c|c|c|c|c|}
\hline 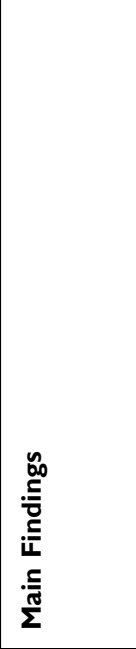 & 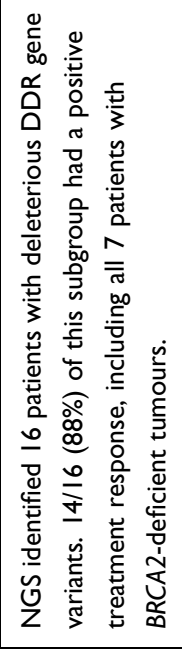 & 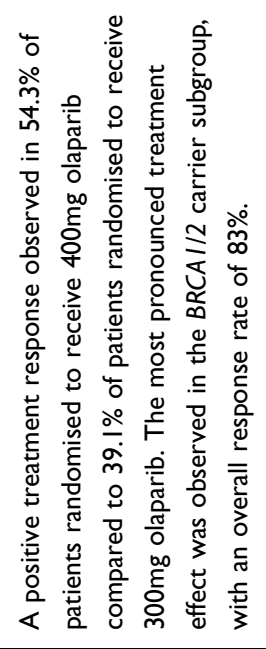 & 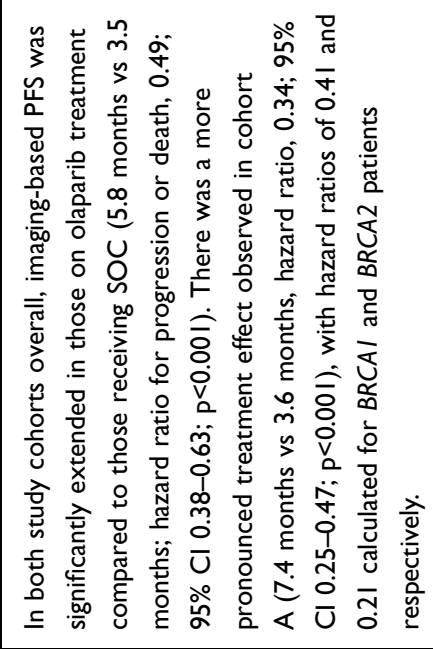 & 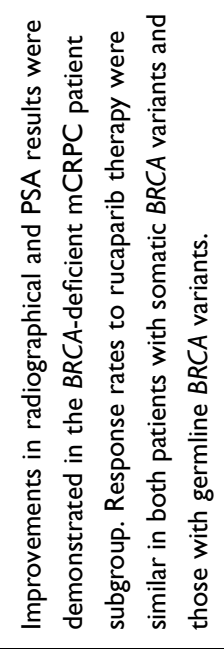 & \\
\hline 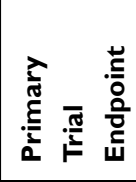 & 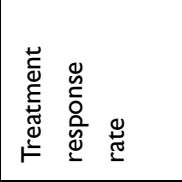 & 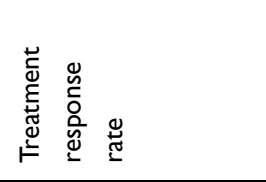 & 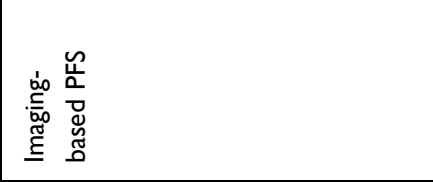 & 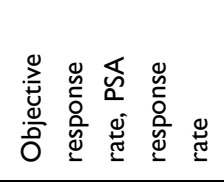 & 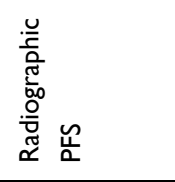 \\
\hline 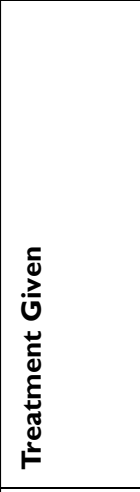 & 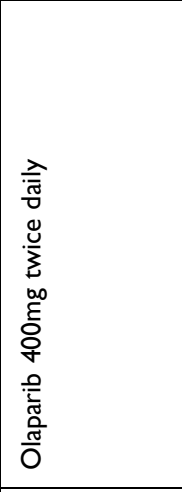 & 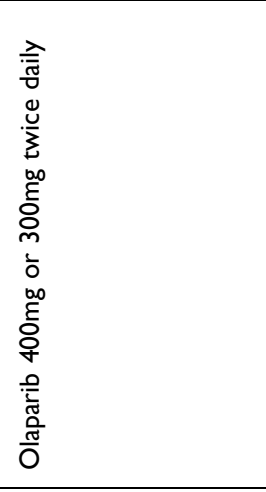 & 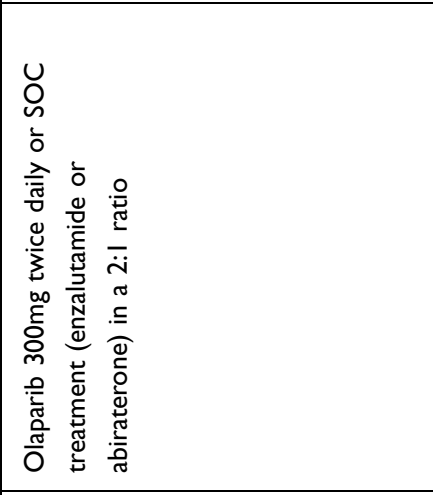 & 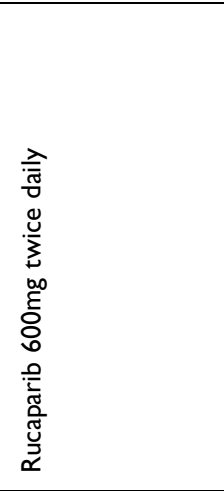 & 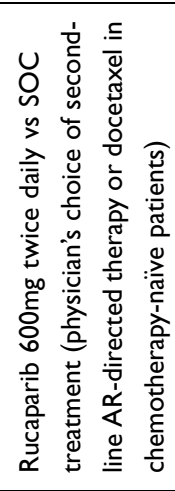 \\
\hline 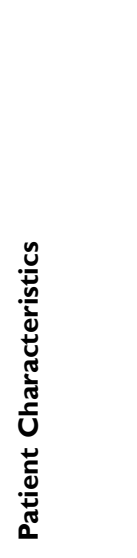 & 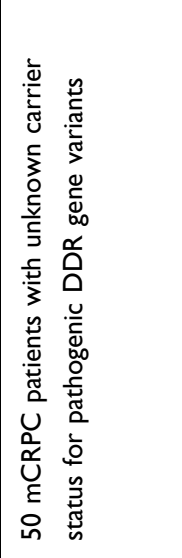 & 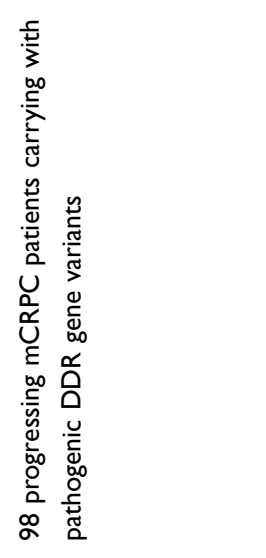 & 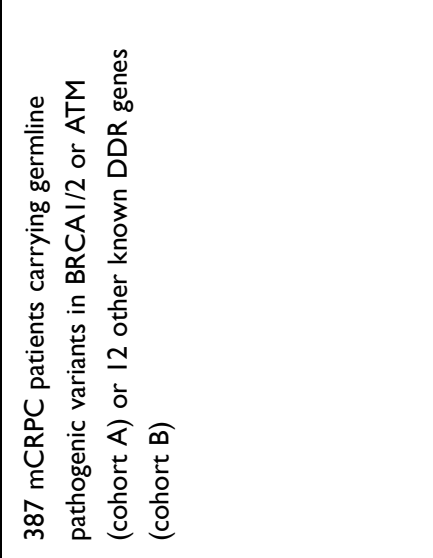 & 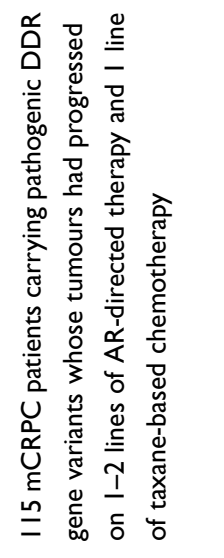 & 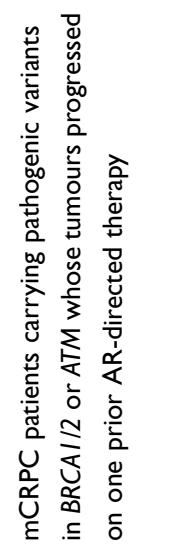 \\
\hline 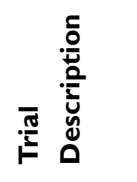 & 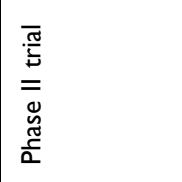 & 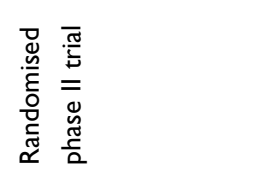 & 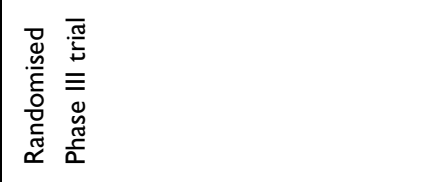 & 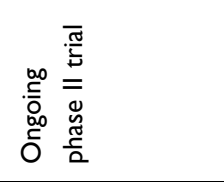 & 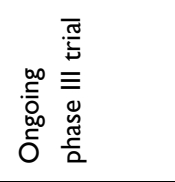 \\
\hline 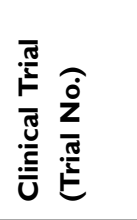 & 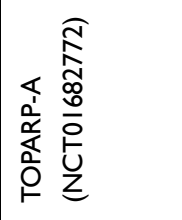 & 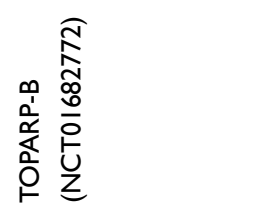 & 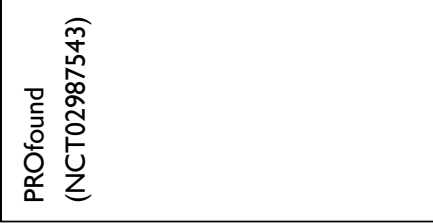 & 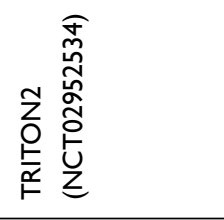 & 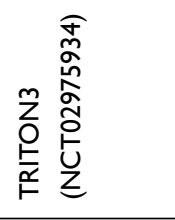 \\
\hline
\end{tabular}


the mutational landscape of the tumour. These reports support the utility of circulating tumour DNA (ctDNA) analysis monitoring to predict PARP inhibitor resistance in mCRPC patients.

\section{Platinum-Based Chemotherapy}

In recent years platinum-based chemotherapy has shown efficacy in the management of $\mathrm{mCRPC}$ associated with pathogenic DDR gene variants including BRCA2. ${ }^{37-39}$ Platinum-based chemotherapeutic agents work by generating cross-links between purine bases in DNA which disrupts DNA repair, causing cell death via apoptosis. ${ }^{59}$

Platinum-based chemotherapy is not routinely used to treat mCRPC based on evidence from trials which did not show overall survival benefit from standard of care. ${ }^{60}$ However, in studies specifically selecting mCRPC patients with pathogenic variants in recognised DDR genes, ${ }^{37-39,61,62}$ platinum-based chemotherapy was found to ameliorate patient quality of life by decelerating tumour progression (Table 2). Reports by Mota et $\mathrm{al}^{63}$ and Simmons et $\mathrm{al}^{64}$ (Table 2) highlight the challenge of tumour resistance which is especially important in $B R C A$ associated PCs which have already been recognised as difficult to treat.

\section{Identification of BRCA2-Deficient Prostate Cancer}

For our patient in Figure 1, it is important to diagnose that he has BRCA2 deficient PC not only for his immediate therapeutic management, but also to consider any possible heritable predisposition to cancer which may require wider cascade screening in the family. Evidence suggesting a $B R C A 2$ deficient $\mathrm{PC}$ can be acquired from multiple sources.

\section{Tumour Phenotype and Somatic Pathogenic Variants}

As previously discussed, $B R C A 2$ deficient $\mathrm{PC}$ often presents with poorer prognostic indicators than $B R C A$ proficient $\mathrm{PC}$, which may trigger suspicion in the treating clinician. ${ }^{11,18}$ Identification of specific biallelic pathogenic variants in $B R C A 2$ can be undertaken by next-generation sequencing (NGS) of tumour-derived DNA. From February 2021, the UK National Genomic Test Directory ${ }^{65}$ specified that somatic gene sequencing of $B R C A 1$ and $B R C A 2$ via NGS panel approaches should be undertaken for all PCs, with the addition of $A T M / C D K 12$ for metastatic resistant PC cases. This standard of care pathway should now be implemented by all seven Genomic Laboratory Hubs (GLHs) in the UK, reducing inequities in testing pathways which have previously existed in the UK, and leading to the identification of more $B R C A 2$ deficient PC. The identification of a somatic pathogenic variant in the $B R C A 1 / 2$ genes in PC should then trigger germline testing for inherited susceptibility according to the European Society of Medical Oncology (ESMO) guidelines. ${ }^{66}$ Somatic small panel testing is likely to be expanded to a wider number of DDR-related genes through gene panel testing, with likely expansion of tumour testing to whole genomes in the future. Whole genome somatic NGS analysis enables identification of driver mutations driving oncogenesis, but in addition enables the identification of mutational signatures, and tumour mutational burden, which can provide evidence for DDRd driving oncogenesis and precision medicine approaches. ${ }^{67}$

\section{Identification of BRCA2-Related Germline Susceptibility to Prostate Cancer}

Family history is a widely established PC risk factor, with some families displaying significant aggregation of PC cases; a man with a first-degree relative affected by the disease has at least twice the chance of developing this condition compared with the general population. Current access to $B R C A$ germline genetic testing for PC patients in the UK relies on them meeting National Genomic Test Directory eligibility criteria R208 (Hereditary Breast and Ovarian Cancer) in which family history is an essential component. ${ }^{68}$ Given the primary focus on breast and ovarian cancer in the eligibility criteria and the fact that systematic family history assessments for those diagnosed with PC is not well embedded within clinical pathways, men presenting with PC are likely to be underserved with respect to germline genetic testing. More robust educational and training is required in secondary care to ensure documentation and collection of family history in men with PC to ensure eligible men, such as our proband from Figure 1, are identified as having likely genetic susceptibility requiring germline testing.

Historically, germline genetic testing of PC patients typically involves predictive testing of a known gene in patients with a previously identified familial variant increasing cancer risk, or, diagnostic genetic testing of $B R C A 1 / 2$ in the context of a significant family history of breast, ovarian and prostate cancer. In our family in Figure 1, diagnostic $B R C A$ testing in such pedigrees has often been instigated by 


\begin{tabular}{|c|c|c|c|c|c|c|}
\hline 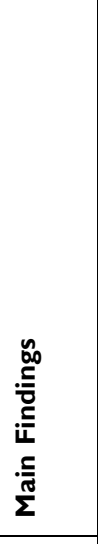 & 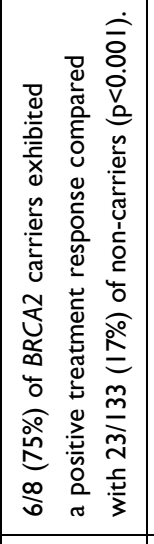 & 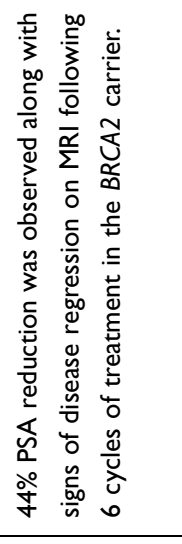 & 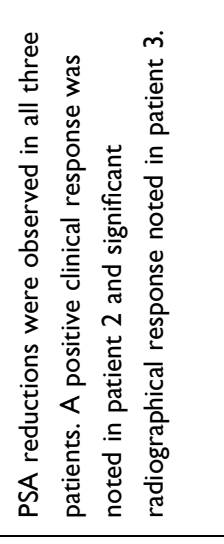 & 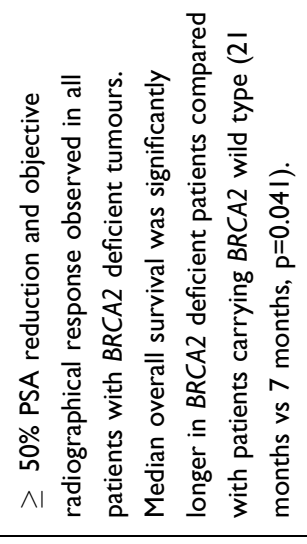 & 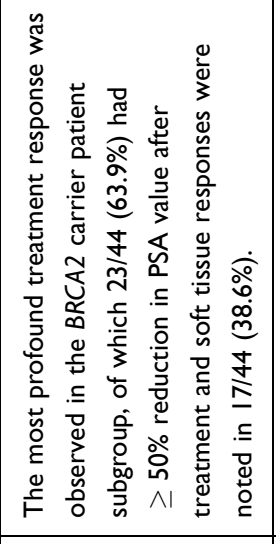 & 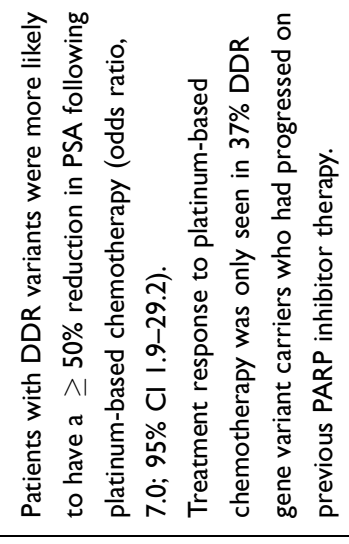 \\
\hline 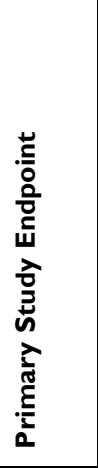 & 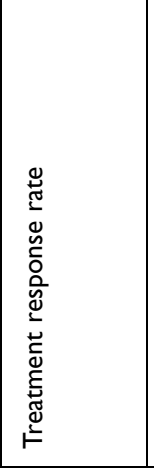 & 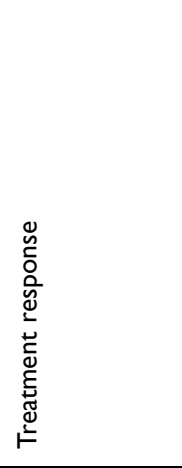 & 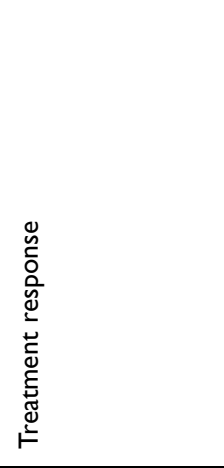 & 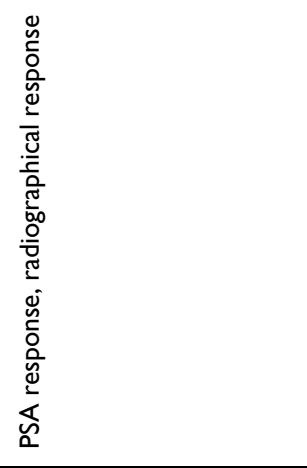 & 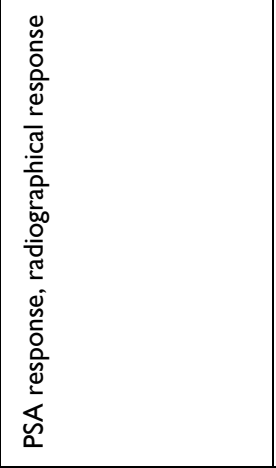 & 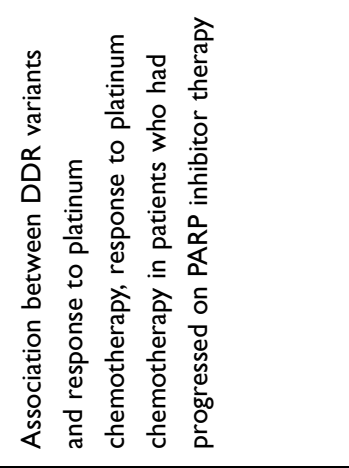 \\
\hline 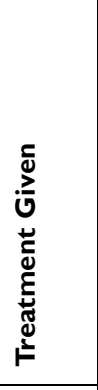 & 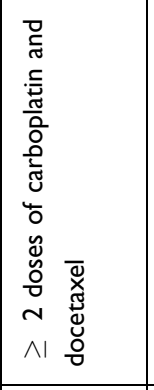 & 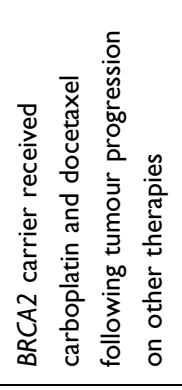 & 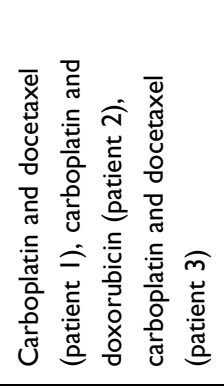 & 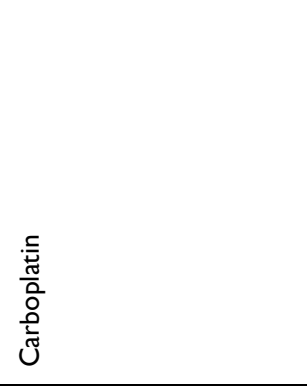 & 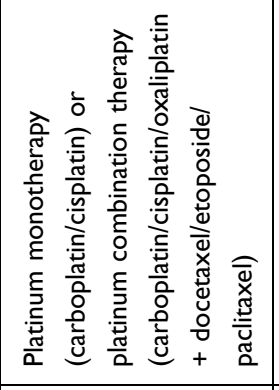 & 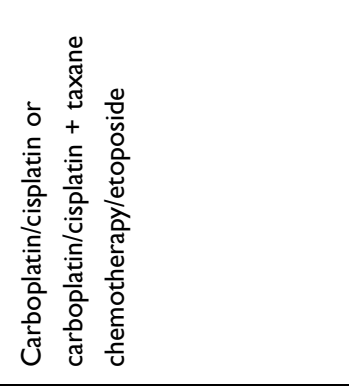 \\
\hline 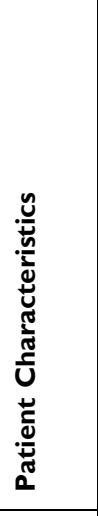 & 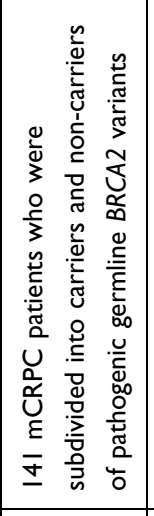 & 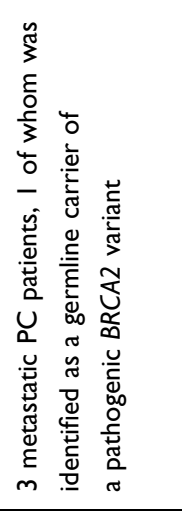 & 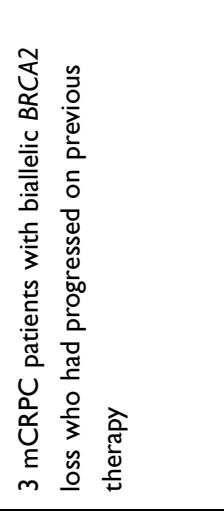 & 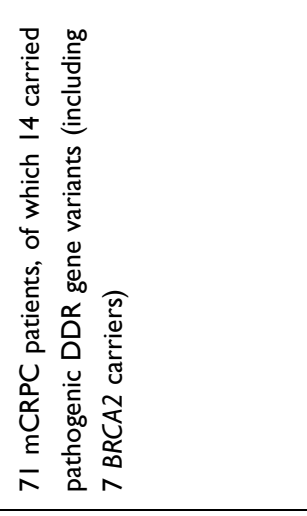 & 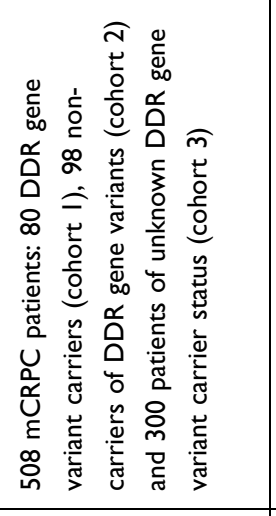 & 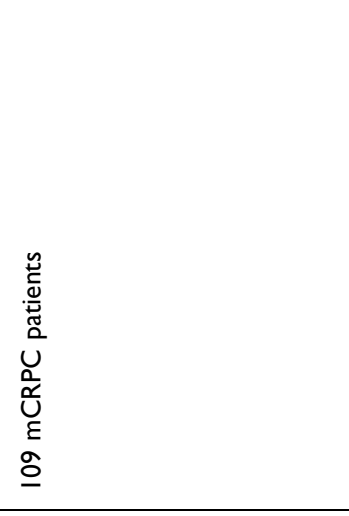 \\
\hline 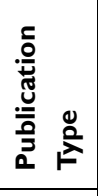 & 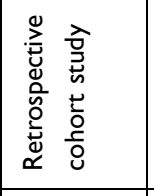 & 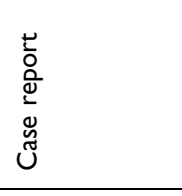 & 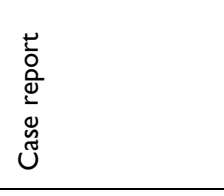 & 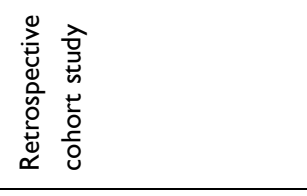 & 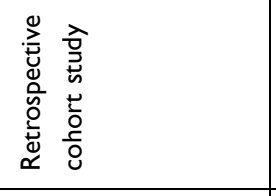 & 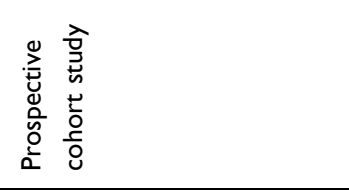 \\
\hline 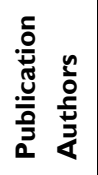 & 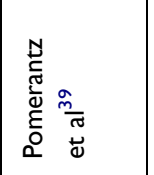 & 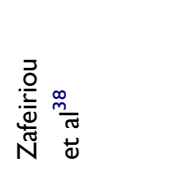 & 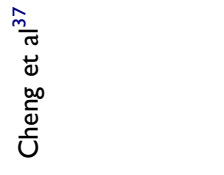 & 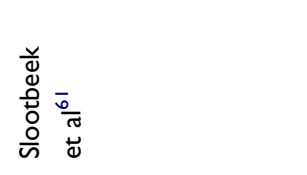 & 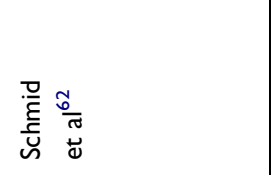 & $\begin{array}{l}\frac{5}{5} \\
\frac{0}{0} \\
\frac{0}{0} \\
\frac{\pi}{0} \\
\frac{0}{0}\end{array}$ \\
\hline
\end{tabular}




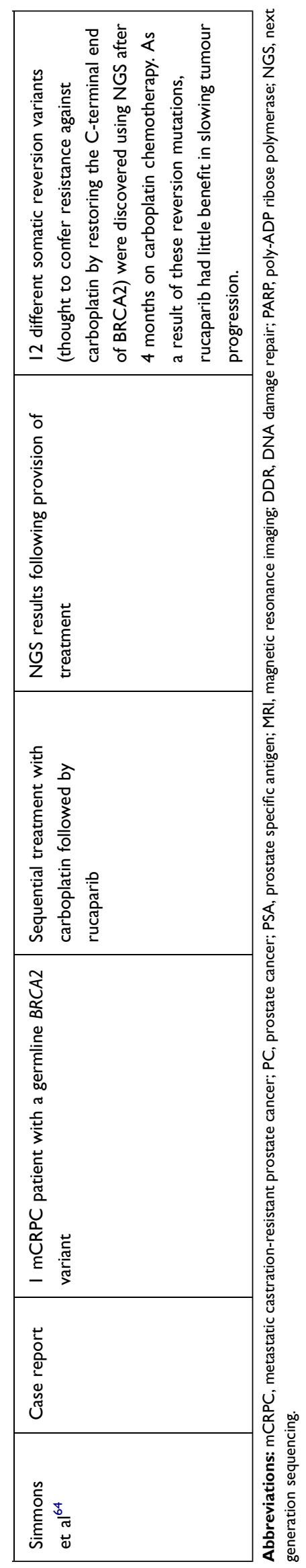

a female presenting with breast or ovarian cancer rather than a male presenting with PC. To widen our ability to identify germline susceptibility to PC, diagnostic gene panel testing in PC patients of PC-associated DDR genes (cancer susceptibility genes) where a family history suggestive of inherited predisposition is absent will detect additional germline gene carriers. ${ }^{10}$

The detection of germline variants can (i) inform choice of treatment, (ii) facilitate genetic testing of atrisk family members (cascade screening), and (iii) help to determine the risk of developing other cancer types associated with the genes where variants were identified. ${ }^{9,69}$ It is therefore important that novel strategies to improve identification of carriers are being implemented.

In our family in Figure 1, the brother of our proband has a $50 \%$ ( 1 in 2 ) chance of also carrying the germline $B R C A 2$ pathogenic variant identified in his brother. $\mathrm{He}$ should be offered a predictive genetic test via clinical genetics services to establish his own risk. In this case, predictive genetic testing identified that the brother also carries the BRCA2 pathogenic variant. This should now facilitate entry of the unaffected brother into Screening, Prevention and Early Detection (SPED) pathways. The sister of the proband with breast cancer is likely to also carry the $B R C A 2$ pathogenic variant but should also be offered germline predictive testing to clarify. If shown to carry the variant she will need discussions about considering risk reducing bilateral salpingo-oophorectomy to reduce her risk of ovarian cancer. The BRCA2 pathogenic variant is likely to have been inherited from the deceased mother who died of ovarian cancer, but cascade testing to the maternal uncles and cousins should be initiated to identify all at risk individuals. The father could be offered predictive testing if no maternal relative is identified with the BRCA2 pathogenic variant to ensure he is not a carrier, as occasionally, phenocopies of cancer diagnoses can mask the side of the family from which the variant was inherited.

Barriers to access to SPED for unaffected male $B R C A 2$ carriers exist across healthcare systems. There is a lack of awareness and understanding among male $B R C A$-carriers about their increased risk of developing $B R C A$-associated cancers, which include PC, pancreatic cancer and male breast cancer, and this can have a detrimental effect on health outcomes. ${ }^{70}$ Contributing factors to misinformation among male $B R C A$-carriers include (i) limited availability of relevant information and resources pertaining to genetic 
risk of $B R C A$-associated cancers such as $\mathrm{PC}$ and male breast cancer, ${ }^{71-73}$ and (ii) lack of awareness among healthcare personnel about men's inherited cancer predisposition and available treatment options. ${ }^{74}$ BRCA1/2 carriers are labelled as persons with "Hereditary Breast and Ovarian Cancer syndrome" 75 which is misleading because $B R C A 1 / 2$ variants increase the risk of other cancers like $\mathrm{PC}$, pancreatic cancer and melanoma, ${ }^{76,77}$ but it also feminizes the condition ${ }^{73,78}$ leading to stigma within the male population.

Improved education and training around identification of genetic susceptibility to PC, more streamlined access to family history assessment, somatic and germline testing for PC patients will all increase identification of individuals with inherited susceptibility to PC. BRCA-risk information specifically adapted for the male population will also aid the promotion of more proactive health behaviours which in turn enable earlier detection of BRCA-associated disease in male $B R C A 2$ carriers. $^{70}$

\section{Prostate Cancer Screening in Unaffected BRCA2 Mutation Carriers}

Consider now the brother of our proband from Figure 1. We have identified he has an increased likelihood of developing $B R C A 2$-related PC, and he will want to know how this risk may be managed.

Whilst measuring serum concentrations of PSA as a means of screening for $\mathrm{PC}$ has become common practice, ${ }^{79}$ there are no universally accepted PC screening guidelines for men. ${ }^{80}$ Screening the general population for PC using PSA testing is not currently recommended based on the results of previous research, ${ }^{81-85}$ which highlights the low specificity of the test.

Data from IMPACT study, ${ }^{80,86}$ an international multicentre PC screening study investigating the utilisation of PSA testing in BRCA1/2 carrier males, have suggested that PSA testing in these men (who are at increased risk of PC) may be of greater clinical benefit than screening the general population. Following the completion of the first IMPACT study screening round, ${ }^{80}$ data showed that in BRCA2 carriers, the positive predictive value (PPV) of biopsy using a PSA threshold of $3.0 \mathrm{ng} / \mathrm{mL}$ was $48 \%$, compared with a lower $33.3 \%$ PPV seen in the control group. In addition, there was a higher frequency of intermediate-high risk PC detected in BRCA2 carriers with PSA values above the $3.0 \mathrm{ng} / \mathrm{mL}$ threshold for further investigation with biopsy. It was also noted the males diagnosed with PC below the age of 50 years were all $B R C A 1 / 2$ carriers, and BRCA2 carriers reaching the 3.0ng/ $\mathrm{mL}$ PSA threshold were significantly younger than their counterparts with elevated PSA values. After 3 more years of follow-up (4 screening rounds), data analysis reiterated the utility of PSA screening in $B R C A 1 / 2$ carriers described previously. When compared with non- $B R C A 2$ carriers, $B R C A 2$ carriers had a significantly higher PPV of PSA $>3.0 \mathrm{ng} / \mathrm{mL}(31 \%$ vs $18 \%$; $\mathrm{p}=0.025)$, a higher PC incidence rate per 1000 person years (19.4 vs $12.0 ; \mathrm{p}=0.03)$, a significantly higher frequency of intermediate-high risk $\mathrm{PC}(\mathrm{p}=0.011)$ and were significantly younger at the time of PC diagnosis $(\mathrm{p}=0.044)$, with the youngest age of onset being recorded in a 41-year-old BRCA2 carrier. Overall, the results so far from the ongoing IMPACT study further substantiate the earlier age of onset and more aggressive PC phenotype seen in BRCA2 carriers which has been widely reported throughout the literature, ${ }^{11,31-34,36,87}$ and also highlights the efficacy of using PSA testing in this patient subgroup.

In another prospective PC screening study, Segal et al ${ }^{88}$ sought to investigate the use of PSA testing and multiparametric magnetic resonance imaging (mpMRI) in 188 male $B R C A 1 / 2$ carriers. Whilst MRI is widely used for breast cancer screening in female $B R C A 1 / 2$ carriers, ${ }^{89}$ this study was the first to investigate the use of this imagine modality for PC screening. Prostate biopsies were offered to patients with either an elevated PSA value (PSA $>3 \mathrm{ng} /$ $\mathrm{mL}$ or elevated age-stratified PSA) and/or a suspicious prostatic lesion on mpMRI (PI-RADS $\geq 3$ ). Of these patients, 92 men (85\%) underwent a prostate biopsy and PC was detected in 16 men (8.5\%). Amongst the 92 men having a prostate biopsy, 5 different PC screening strategies making use of either (i) PSA testing alone, (ii) mpMRI alone or (iii) both PSA testing and mpMRI were compared using decision curve analysis. Overall, using mpMRI in isolation proved to be the best screening tool, picking up 15/16 cancers. Interestingly, in BRCA1/2 carriers under the age of 55 years, using mpMRI irrespective of PSA value had the most benefit whilst PSA screening on its own had zero net benefit. In men older than 55 years, triaging with PSA testing before offering mpMRI had the most benefit.

Based on the results of the IMPACT study ${ }^{80,86}$ and those reported by Segal et al, ${ }^{88}$ national and/or international guidelines for unaffected male $B R C A 2$ carriers, such as the brother of our proband in Figure 1, are likely to be 
published in the near future. This is likely to specify PSA testing for male $B R C A 2$ carriers from age 40 , with subsequent investigations required for individuals with PSA $\geq 3$ $\mathrm{ng} / \mathrm{mL}$.

\section{Conclusion}

In this review article, we have discussed the investigation and management of $B R C A 2$ deficient PC using a case study of a family with a pathogenic germline $B R C A 2$ variant. We have outlined how BRCA2 deficient PC in the proband might present, and management options which may have specific relevance for $B R C A 2$ deficient PC, such as PARP inhibitors and platinum-based chemotherapy. We have also highlighted the need to distinguish between somatic and germline BRCA2 pathogenic variants which may have relevance for cancer predisposition in other family members, and the screening which can be offered to unaffected male $B R C A 2$ carriers. The inclusion of all these facets to $B R C A 2$ deficient PC investigation and management in our review provides a comprehensive overview of the clinical approach to a family in which BRCA2 deficient PC is diagnosed. The rapid advances in our understanding of the molecular pathogenesis of DDRd PC and new treatment paradigms, alongside the widened access to both somatic and germline genetic analysis for PC patients and their families will hopefully enable the robust implementation of highquality evidence based clinical pathways for both the management and identification of $B R C A$ deficient PC and improved screening, early detection and prevention strategies for individuals at increased genetic risk of PC.

\section{Acknowledgments}

We acknowledge support from The National Institute of Health Research to the Biomedical Research Centre at The Institute of Cancer Research and Royal Marsden NHS Foundation Trust. JMcH is supported by the Biomedical Research Centre and the Movember Centre of Excellence and Prostate Cancer UK.

We also would like to thank Rosalind Eeles, Professor of Oncogenetics at the Institute of Cancer Research, Clinician at the Royal Marsden NHS Foundation Trust, for comments on the draft manuscript.

\section{Disclosure}

The authors report no conflict of interest in this work.

\section{References}

1. Sung H, Ferlay J, Siegel RL, et al. Global cancer statistics 2020: GLOBOCAN estimates of incidence and mortality worldwide for 36 cancers in 185 countries. CA Cancer J Clin. 2021:1-41. doi:10.3322/ caac. 21660 .

2. Hjelmborg JB, Scheike T, Holst K, et al. The heritability of prostate cancer in the Nordic twin study of cancer. Cancer Epidemiol Biomarkers Prev. 2014;23(11):2303-2310. doi:10.1158/1055-9965. EPI-13-0568

3. Attard G, Parker C, Eeles RA, et al. Prostate cancer. Lancet. 2016;387(10013):70-82. doi:10.1016/S0140-6736(14)61947-4

4. Farashi S, Kryza T, Clements J, Batra J. Post-GWAS in prostate cancer: from genetic association to biological contribution. Nat Rev Cancer. 2019;19(1):46-59. doi:10.1038/s41568-018-0087-3

5. Sipeky C, Talala KM, Tammela TLJ, Taari K, Auvinen A, Schleutker J. Prostate cancer risk prediction using a polygenic risk score. Sci Rep. 2020;10(1). doi:10.1038/s41598-020-74172-z

6. Zhen JT, Syed J, Nguyen KA, et al. Genetic testing for hereditary prostate cancer: current status and limitations. Cancer. 2018;124 (15):3105-3117. doi:10.1002/cncr.31316

7. Robinson D, van Allen EM, Wu YM, et al. Integrative clinical genomics of advanced prostate cancer. Cell. 2015;161 (5):1215-1228. doi:10.1016/j.cell.2015.05.001

8. Abeshouse A, Ahn J, Akbani R, et al. The molecular taxonomy of primary prostate cancer. Cell. 2015;163(4):1011-1025. doi:10.1016/j. cell.2015.10.025

9. Pilarski R. The role of BRCA testing in hereditary pancreatic and prostate cancer families. Am Soc Clin Oncol Educ Book. 2019;39 (39):79-86. doi:10.1200/EDBK_238977

10. Das S, Salami SS, Spratt DE, Kaffenberger SD, Jacobs MF, Morgan TM. Bringing prostate cancer germline genetics into clinical practice. $J$ Urol. 2019;202(2):223-230. doi:10.1097/JU.0000000000000137

11. Nombela P, Lozano R, Aytes A, Mateo J, Olmos D, Castro E. BRCA2 and other DDR genes in prostate cancer. Cancers. 2019;11 (3):352. doi:10.3390/cancers 11030352

12. Breast Cancer Linkage Consortium. Cancer risks in BRCA2 mutation carriers. J Natl Cancer Inst. 1999;91(15):1310-1316. doi:10.1093/ jnci/91.15.1310

13. Kote-Jarai Z, Leongamornlert D, Saunders E, et al. BRCA2 is a moderate penetrance gene contributing to young-onset prostate cancer: implications for genetic testing in prostate cancer patients. Br J Cancer. 2011;105(8):1230-1234. doi:10.1038/bjc.2011.383

14. Edwards SM, Kote-Jarai Z, Meitz J, et al. Two percent of men with early-onset prostate cancer harbor germline mutations in the BRCA2 gene. Am J Hum Genet. 2003;72(1):1-12. doi:10.1086/345310

15. Agalliu I, Karlins E, Kwon EM, et al. Rare germline mutations in the BRCA2 gene are associated with early-onset prostate cancer. $\mathrm{Br}$ $J$ Cancer. 2007;97(6):826-831. doi:10.1038/sj.bjc.6603929

16. Schrader KA, Cheng DT, Joseph V, et al. Germline variants in targeted tumor sequencing using matched normal DNA. JAMA Oncol. 2016;2(1):104. doi:10.1001/jamaoncol.2015.5208

17. Mateo J, Carreira S, Sandhu S, et al. DNA-repair defects and olaparib in metastatic prostate cancer. $N$ Engl $J$ Med. 2015;373 (18):1697-1708. doi:10.1056/nejmoa1506859

18. Castro E, Eeles R. The role of BRCA1 and BRCA2 in prostate cancer. Asian $J$ Androl. 2012;14(3):409-414. doi:10.1038/ aja.2011.150

19. Jenzer $M, K e ß P$, Nientiedt $C$, et al. The BRCA2 mutation status shapes the immune phenotype of prostate cancer. Cancer Immunol Immunother. 2019;68(10):1621-1633. doi:10.1007/s00262-01902393-x

20. Edwards SM, Dunsmuir WD, Gillett CE, et al. Immunohistochemical expression of BRCA2 protein and allelic loss at theBRCA2 locus in prostate cancer. Int $J$ Cancer. 1998;78(1):1-7. doi:10.1002/(SICI) 1097-0215(19980925)78:1<1::AID-IJC1>3.0.CO;2-U 
21. Shore N, Oliver L, Shui I, et al. Systematic literature review of the epidemiology of advanced prostate cancer and Associated homologous recombination repair gene alterations. J Urol. 2021;205 (4):977-986. doi:10.1097/JU.0000000000001570

22. Antonarakis ES, Gomella LG, Petrylak DP. When and how to use PARP inhibitors in prostate cancer: a systematic Review of the literature with an update on on-going Trials. Eur Urol Oncol. 2020;3(5):594-611. doi:10.1016/j.euo.2020.07.005

23. Ratta R, Guida A, Scotté F, et al. PARP inhibitors as a new therapeutic option in metastatic prostate cancer: a systematic review. Prostate Cancer Prostatic Dis. 2020;23(4):549-560. doi:10.1038/ s41391-020-0233-3

24. Swift SL, Lang SH, White H, Misso K, Kleijnen J, Quek RG. Effect of DNA damage response mutations on prostate cancer prognosis: a systematic review. Future Oncol. 2019;15(28):3283-3303. doi:10.2217/fon-2019-0298

25. Lang S, Swift S, White H, Misso K, Kleijnen J, Quek R. A systematic review of the prevalence of DNA damage response gene mutations in prostate cancer. Int J Oncol. 2019;55(3):597-616. doi:10.3892/ijo.2019.4842

26. Armstrong N, Quek RG, Ryder S, et al. DNA damage repair gene mutation testing and genetic counseling in men with/without prostate cancer: a systematic review. Future Oncol. 2021;17(7):853-864. doi: $10.2217 /$ fon-2020-0569

27. Oh M, Alkhushaym N, Fallatah S, et al. The association of BRCA1 and BRCA2 mutations with prostate cancer risk, frequency, and mortality: a meta-analysis. Prostate. 2019;79(8):880-895. doi: $10.1002 /$ pros. 23795

28. Ramakrishnan Geethakumari P, Schiewer MJ, Knudsen KE, Kelly WK. PARP Inhibitors in Prostate Cancer. Curr Treat Options Oncol. 2017;18(6). doi:10.1007/s11864-017-0480-2

29. National Institute for Heath and Care Excellence. Prostate cancer: diagnosis and management NICE Guideline; 2019. Available from: www.nice.org.uk/guidance/ng131. Accessed May 5, 2021.

30. Carter HB, Helfand B, Mamawala M, et al. Germline mutations in ATM and BRCA1/2 are associated with grade reclassification in men on active surveillance for prostate cancer. Eur Urol. 2019;75 (5):743-749. doi:10.1016/j.eururo.2018.09.021

31. Gleicher S, Kauffman EC, Kotula L, Bratslavsky G, Vourganti S. Implications of high rates of metastatic prostate cancer in BRCA2 mutation carriers. Prostate. 2016;76(13):1135-1145. doi:10.1002/ pros.23204

32. Wokołorczyk D, Kluźniak W, Huzarski T, et al. Mutations in ATM, NBN and BRCA2 predispose to aggressive prostate cancer in Poland. Int J Cancer. 2020;147(10):2793-2800. doi:10.1002/ijc.33272

33. Na R, Zheng SL, Han M, et al. Germline mutations in ATM and BRCA1/2 distinguish risk for lethal and indolent prostate cancer and are associated with early age at death. Eur Urol. 2017;71(5):740-747. doi:10.1016/j.eururo.2016.11.033

34. Castro E, Goh C, Leongamornlert D, et al. Effect of BRCA mutations on metastatic relapse and cause-specific survival after radical treatment for localised prostate cancer. Eur Urol. 2015;68(2):186-193. doi:10.1016/j.eururo.2014.10.022

35. Akbari MR, Wallis CJD, Toi A, et al. The impact of a BRCA2 mutation on mortality from screen-detected prostate cancer. $\mathrm{Br}$ J Cancer. 2014;111(6):1238-1240. doi:10.1038/bjc.2014.428

36. Castro E, Goh C, Olmos D, et al. Germline BRCA mutations are associated with higher risk of nodal involvement, distant metastasis, and poor survival outcomes in prostate cancer. J Clin Oncol. 2013;31 (14):1748-1757. doi:10.1200/JCO.2012.43.1882

37. Cheng HH, Pritchard CC, Boyd T, Nelson PS, Montgomery B. Biallelic inactivation of BRCA2 in platinum-sensitive metastatic castration-resistant prostate cancer. Eur Urol. 2016;69(6):992-995. doi:10.1016/j.eururo.2015.11.022
38. Zafeiriou Z, Bianchini D, Chandler R, et al. Genomic analysis of three metastatic prostate cancer patients with exceptional responses to carboplatin indicating different types of DNA repair deficiency. Eur Urol. 2019;75(1):184-192. doi:10.1016/j. eururo.2018.09.048

39. Pomerantz MM, Spisák S, Jia L, et al. The association between germline BRCA2 variants and sensitivity to platinum-based chemotherapy among men with metastatic prostate cancer. Cancer. 2017;123(18):3532-3539. doi:10.1002/cncr.30808

40. Durkacz BW, Omidiji O, Gray DA, Shall S. (ADP-ribose)n participates in DNA excision repair. Nature. 1980;283(5747):593-596. doi:10.1038/283593a0

41. Bryant HE, Schultz N, Thomas HD, et al. Specific killing of BRCA2-deficient tumours with inhibitors of poly(ADP-ribose) polymerase. Nature. 2005;434(7035):913-917. doi:10.1038/nature03443

42. Virtanen V, Paunu K, Ahlskog J, Varnai R, Sipeky C, Sundvall M. PARP inhibitors in prostate cancer-the preclinical rationale and current clinical development. Genes. 2019;10(8):565. doi:10.3390/ genes 10080565

43. Rimar KJ, Tran PT, Matulewicz RS, Hussain M, Meeks JJ. The emerging role of homologous recombination repair and PARP inhibitors in genitourinary malignancies. Cancer. 2017;123 (11):1912-1924. doi:10.1002/cncr.30631

44. Farmer H, McCabe N, Lord CJ, et al. Targeting the DNA repair defect in BRCA mutant cells as a therapeutic strategy. Nature. 2005;434(7035):917-921. doi:10.1038/nature03445

45. Risdon EN, Chau CH, Price DK, Sartor O, Figg WD. PARP inhibitors and prostate cancer: to infinity and beyond BRCA. Oncologist. 2021;26(1). doi:10.1634/theoncologist.2020-0697

46. de Bono J, Mateo J, Fizazi K, et al. Olaparib for metastatic castration-resistant prostate cancer. $N$ Engl J Med. 2020;382 (22):2091-2102. doi:10.1056/NEJMoa1911440

47. Abida W, Campbell D, Patnaik A, et al. Preliminary results from the TRITON2 study of rucaparib in patients (pts) with DNA damage repair (DDR)-deficient metastatic castration-resistant prostate cancer (mCRPC): updated analyses. Ann Oncol. 2019:30. doi:10.1093/ annonc/mdz248.003.

48. Mateo J, Porta N, Bianchini D, et al. Olaparib in patients with metastatic castration-resistant prostate cancer with DNA repair gene aberrations (TOPARP-B): a multicentre, open-label, randomised, Phase 2 trial. Lancet Oncol. 2020;21(1):162-174. doi:10.1016/ S1470-2045(19)30684-9

49. Abida W, Patnaik A, Campbell D, et al. Rucaparib in men with metastatic castration-resistant prostate cancer harboring a BRCA1 or BRCA2 gene alteration. $J$ Clin Oncol. 2020;38(32):3763-3772. doi:10.1200/JCO.20.01035

50. Bouwman P, Jonkers J. Molecular pathways: how can BRCA-mutated tumors become resistant to PARP inhibitors? Clin Cancer Res. 2014;20 (3):540-547. doi:10.1158/1078-0432.CCR-13-0225

51. Dhillon KK, Swisher EM, Taniguchi T. Secondary mutations of BRCA1/2 and drug resistance. Cancer Sci. 2011;102(4):663-669. doi:10.1111/j.1349-7006.2010.01840.x

52. Lord CJ, Ashworth A. PARP inhibitors: synthetic lethality in the clinic. Science. 2017;355(6330):1152-1158. doi:10.1126/science. aam7344

53. Barber LJ, Sandhu S, Chen L, et al. Secondary mutations in BRCA2 associated with clinical resistance to a PARP inhibitor. $J$ Pathol. 2013;229(3):422-429. doi:10.1002/path.4140

54. Edwards SL, Brough R, Lord CJ, et al. Resistance to therapy caused by intragenic deletion in BRCA2. Nature. 2008;451 (7182):1111-1115. doi:10.1038/nature06548

55. Sakai W, Swisher EM, Jacquemont C, et al. Functional restoration of BRCA2 protein by secondary BRCA2 mutations in BRCA2-mutated ovarian carcinoma. Cancer Res. 2009;69(16):6381-6386. doi:10.1158/0008-5472.CAN-09-1178 
56. Sakai W, Swisher EM, Karlan BY, et al. Secondary mutations as a mechanism of cisplatin resistance in BRCA2-mutated cancers. Nature. 2008;451(7182):1116-1120. doi:10.1038/nature06633

57. Carneiro BA, Collier KA, Nagy RJ, et al. Acquired resistance to poly (ADP-ribose) polymerase inhibitor olaparib in brca2-associated prostate cancer resulting from biallelic BRCA2 reversion mutations restores both germline and somatic loss-of-function mutations. JCO Precis Oncol. 2018;(2):1-8. doi:10.1200/PO.17.00176

58. Ma Y, He L, Huang Q, et al. Response to olaparib in metastatic castration-resistant prostate cancer with germline BRCA2 mutation: a case report. BMC Med Genet. 2018;19(1). doi:10.1186/s12881-0180703-9

59. Dasari S, Bernard Tchounwou P. Cisplatin in cancer therapy: molecular mechanisms of action. Eur J Pharmacol. 2014;740:740. doi:10.1016/j.ejphar.2014.07.025

60. Bouman-Wammes EW, van den Berg HP, de Munck L, et al. A randomised Phase II trial of docetaxel versus docetaxel plus carboplatin in patients with castration-resistant prostate cancer who have progressed after response to prior docetaxel chemotherapy: the RECARDO trial. Eur J Cancer. 2018;90:90. doi:10.1016/j. ejca.2017.11.021

61. Slootbeek PHJ, Duizer ML, Doelen MJ, et al. Impact of DNA damage repair defects and aggressive variant features on response to carboplatin-based chemotherapy in metastatic castration-resistant prostate cancer. Int J Cancer. 2021;148(2):385-395. doi:10.1002/ijc.33306

62. Schmid S, Omlin A, Higano C, et al. Activity of platinum-based chemotherapy in patients with advanced prostate cancer with and without DNA repair gene aberrations. JAMA Netw Open. 2020;3 (10):e2021692. doi:10.1001/jamanetworkopen.2020.21692

63. Mota JM, Barnett E, Nauseef JT, et al. Platinum-based chemotherapy in metastatic prostate cancer with DNA repair gene alterations. JCO Precis Oncol. 2020;(4):355-366. doi:10.1200/PO.19.00346

64. Simmons AD, Nguyen M, Pintus E. Polyclonal BRCA2 mutations following carboplatin treatment confer resistance to the PARP inhibitor rucaparib in a patient with $\mathrm{mCRPC}$ : a case report. BMC Cancer. 2020;20(1). doi:10.1186/s12885-020-6657-2

65. National Health Service. 2020/2021 national genomic test directory for cancer; 2020. Available from: https://www.england.nhs.uk/publi cation/national-genomic-test-directories/. Accessed February 6, 2021.

66. Parker C, Castro E, Fizazi K, et al. Prostate cancer: ESMO clinical practice guidelines for diagnosis, treatment and follow-up. Ann Oncol. 2020;31(9):1119-1134. doi:10.1016/j.annonc.2020.06.011

67. Berner AM, Morrissey GJ, Murugaesu N. Clinical analysis of whole genome sequencing in cancer patients. Curr Genet Med Rep. 2019;7 (2):136-143. doi:10.1007/s40142-019-00169-4

68. Eeles R. Genetic predisposition to prostate cancer. Prostate Cancer Prostatic Dis. 1999;2(1):9-15. doi:10.1038/sj.pcan.4500279

69. Sokolova AO, Cheng HH. Genetic Testing in Prostate Cancer. Curr Oncol Rep. 2020;22(1). doi:10.1007/s11912-020-0863-6

70. Dean M, Campbell-Salome G, Rauscher EA. Engaging men with BRCA-related cancer risks: practical advice for BRCA risk management from male stakeholders. Am J Mens Health. 2020;14 (3):155798832092493. doi:10.1177/1557988320924932

71. Donovan T, Flynn M. What makes a man a man? Cancer Nurs. 2007;30(6):464-470. doi:10.1097/01.NCC.0000300173.18584.37

72. Rauscher EA, Dean M, Campbell-Salome G, Barbour JB. "How do we rally around the one who was positive?" Familial uncertainty management in the context of men managing BRCA-related cancer risks. Soc Sci Med. 2019;242. doi:10.1016/j.socscimed.2019.112592

73. Skop M, Lorentz J, Jassi M, Vesprini D, Einstein G. "Guys Don't Have Breasts": the lived experience of men who have BRCA gene mutations and are at risk for male breast cancer. Am J Mens Health. 2018;12(4):961-972. doi:10.1177/1557988317753241
74. Dean M. "You have to be your own advocate": patient self-advocacy as a coping mechanism for hereditary breast and ovarian cancer risk. Womens Health Advocacy. 2019;1-15.

75. Pritchard C. New name for breast-cancer syndrome could help to save lives. Nature. 2019;571(7763):27-29. doi:10.1038/d41586-01902015-7

76. Mahon SM. Cancer risks for men with BRCA1/2 mutations. Oncol Nurs Forum. 2014;41(1). doi:10.1188/14.ONF.99-101

77. Petrucelli N, Daly MB, Pal T. BRCA1- and BRCA2-associated hereditary breast and ovarian cancer. In: Adam MP, Ardinger $\mathrm{HH}$, Pagon RA, et al. editors. GeneReviews ${ }^{\circledR}$ [Internet]; University of Washington: Seattle. Initial Posting: September 4, 1998; Last Update: December 15, 2016. Available from: https://www.ncbi.nlm. nih.gov/books/NBK1247/. Accessed May, 14, 2021.

78. Hesse-Biber S, Within-Gender AC. Differences in medical decision making among male carriers of the BRCA genetic mutation for hereditary breast cancer. Am J Mens Health. 2017;11(5):1444-1459. doi: $10.1177 / 1557988315610806$

79. Vickers AJ, Ulmert D, Sjoberg DD, et al. Strategy for detection of prostate cancer based on relation between prostate specific antigen at age 40-55 and long term risk of metastasis: case-control study. BMJ. 2013;346(apr15 5):f2023-f2023. doi:10.1136/bmj.f2023

80. Bancroft EK, Page EC, Castro E, et al. Targeted prostate cancer screening in BRCA1 and BRCA2 mutation carriers: results from the initial screening round of the IMPACT Study. Eur Urol. 2014;66(3):489-499. doi:10.1016/j.eururo.2014.01.003

81. Andriole GL, Crawford ED, Grubb RL, et al. Prostate cancer screening in the randomized prostate, lung, colorectal, and ovarian cancer screening trial: mortality results after 13 years of follow-up. $J$ Natl Cancer Inst. 2012;104(2):125-132. doi:10.1093/jnci/djr500

82. Schröder FH, Hugosson J, Roobol MJ, et al. Prostate-cancer mortality at 11 years of follow-up. $N$ Engl J Med. 2012;366(11):981-990. doi:10.1056/NEJMoa1113135

83. Roobol MJ, Steyerberg EW, Kranse R, et al. A risk-based strategy improves prostate-specific antigen-driven detection of prostate cancer. Eur Urol. 2010;57(1):79-85. doi:10.1016/j.eururo.2009.08.025

84. Ciatto S, Rubeca T, Confortini M, et al. Free to total PSA ratio is not a reliable predictor of prostate biopsy outcome. Tumori J. 2004;90 (3):324-327. doi:10.1177/030089160409000311

85. Harvey P, Basuita A, Endersby D, Curtis B, Iacovidou A, Walker M. A systematic review of the diagnostic accuracy of prostate specific antigen. BMC Urol. 2009;9(1). doi:10.1186/1471-2490-9-14

86. Page EC, Bancroft EK, Brook MN, et al. Interim results from the IMPACT Study: evidence for prostate-specific antigen screening in BRCA2 mutation carriers. Eur Urol. 2019;76(6):831-842. doi:10.1016/j.eururo.2019.08.019

87. Song WH, Kim SH, Joung JY, et al. Prostate cancer in a patient with a family history of BRCA mutation: a case report and literature Review. J Korean Med Sci. 2017;32(2):377. doi:10.3346/jkms.2017.32.2.377

88. Segal N, Ber Y, Benjaminov O, et al. Imaging-based prostate cancer screening among BRCA mutation carriers-results from the first round of screening. Ann Oncol. 2020;31(11):1545-1552. doi:10.1016/j.annonc.2020.06.025

89. Paluch-Shimon S, Cardoso F, Sessa C, et al. Prevention and screening in BRCA mutation carriers and other breast/ovarian hereditary cancer syndromes: ESMO Clinical Practice Guidelines for cancer prevention and screening. Ann Oncol. 2016:27. doi:10.1093/annonc/mdw327. 


\section{Publish your work in this journal}

The Application of Clinical Genetics is an international, peerreviewed open access journal that welcomes laboratory and clinical findings in the field of human genetics. Specific topics include: Population genetics; Functional genetics; Natural history of genetic disease; Management of genetic disease; Mechanisms of genetic disease;
Counselling and ethical issues; Animal models; Pharmacogenetics; Prenatal diagnosis; Dysmorphology. The manuscript management system is completely online and includes a very quick and fair peerreview system, which is all easy to use. Visit http://www.dovepress. com/testimonials.php to read real quotes from published authors. 